Descargo de responsabilidad: las opiniones expresadas en los manuscritos son responsabilidad exclusiva de los autores. No necesariamente reflejan las opiniones de la editorial ni la de sus miembros.

1 CANIR⿴囗十 NIVERSITARIO DEACAPA

\title{
Algunas consideraciones sobre delitos de infracción de deber
}

\section{Some considerations about duty infection crimes}

Recibido: $20 / 07 / 2021$

Aceptado: $20 / 08 / 2021$

\author{
Bayron Eriberto Quiroa Vargas \\ Maestría en Derecho Procesal Penal \\ Universidad de San Carlos de Guatemala \\ quibay1371@gmail.com
}

\section{Referencia}

Quiroa Vargas, B. E. (2021). Algunas consideraciones sobre delitos de infracción de deber. Revista Académica Sociedad Del Conocimiento Cunzac, 1(1), 9-14. DOI: https://doi.org/10.46780/sociedadcunzac.v1i1.2

\section{Resumen}

El presente artículo materializa un análisis sobre las conductas en las cuales la autoría se ve caracterizada por el hecho de que el funcionario abusa o descuida el deber especial que surge de su rol en la sociedad, que ha puesto en peligro o lesión típica de determinados bienes jurídicos, el tema de las consideraciones en delitos de infracción de deber es un fenómeno social que impera en los países en desarrollo, el cual está enfocado especialmente a los delitos que cometen los funcionarios públicos; siendo que es una manifestación de hecho distinguir la participación del sujeto activo en la comisión de delito de infracción de deber, resulta importante recalcar que en esta clase de delitos intervienen varias personas y por ende es necesario establecer quien es autor directo, autor mediato y coautor y las distintas formas de participación así como los elementos positivos y elementos negativos del delito, en cuanto a la conducta y ausencia de la misma. Prácticamente nos encontramos ante la teoría del dominio funcional del hecho, teoría en la cual los autores se asignan funciones para cometer un hecho; siendo a partir de estos acontecimientos que intervienen algunos tratadistas y les asignan las siguientes denominaciones: "Extraneus", "Intraneus", "Extranei", mismas que exigen que el Ministerio Público debe según la norma penal sustantiva, determinar claramente la participación en el delito, si fue la de autor director, inmediato o coautor y que en la acusación un acto posterior se le exige con mayor claridad el título de la imputación que debe dar a la persona que se está acusando, razón por la cual resultaría ilegitimo un acto del Ministerio Público o el Órgano Jurisdiccional no hacer esa distinción, para poder esclarecer esta teoría que se torna necesaria, por lo se encuentra ante la inexistencia de una regulación legal, teórica y filosófica para la aplicación debido proceso.

\section{Palabras clave}

consideraciones, delito, infracción, deber, autoría

\section{Abstract}

This article materializes an analysis on the behaviors in which the authorship is characterized by the fact that the official abuses or neglects the special duty that arises from his role in society, which has endangered or typical injury to certain assets legal issues, the issue of considerations in crimes of breach of duty is a social phenomenon that prevails in developing countries, which is focused especially on crimes committed by public officials; being that it is a manifestation of fact to distinguish the participation of the active subject in the 
commission of the crime of infringement of duty, it is important to emphasize that in this class of crimes several people intervene and therefore it is necessary to establish who is the direct author, mediate author and co-author and the different forms of participation as well as the positive and negative elements, in terms of behavior and its absence. We are practically before the theory of the functional domain of the fact, a theory in which the authors assign functions to commit an act; being from these events that some writers intervene and assign them from the previous names the following: "Extraneus", "Intraneus", "Extranei", They require that the Public Ministry must, according to the substantive criminal norm, clearly determine the participation in the crime, whether it was the directing, immediate or co-author perpetrator and that in the accusation a subsequent act is required more clearly the title of the crime imputation that must be given to the person who is being accused, which is why it would be illegitimate an act of the Public Ministry or the Jurisdictional Body not to make that distinction, in order to clarify this theory that becomes necessary, so we are faced with the non-existence of a legal, theoretical and philosophical regulation for the application due process.

\section{Keywords}

considerations, crime, infraction, duty, authorship

\section{Introducción}

Como todo individuo domina su propio comportamiento, en tanto no presente defectos de conducción, es entonces el dominio sobre el propio movimiento corporal fundamento del resultado. Este dominio sobre el propio comportamiento es el punto de partida llevado al concepto de la autoría directa o inmediata en todos los códigos penales. De ahí que se afirme, según la teoría del dominio funcional del hecho, que es autor quien domina el evento delictivo; es autor quien tiene las riendas del acontecimiento criminal. Luego el dominio ejercido sobre otros en la autoría mediata y el dominio común mediante división de tareas en la coautoría, son expresiones del concepto tipológico de la teoría del dominio del hecho.

Aunado a las anteriores circunstancias, distintos tratadistas les asignan las siguientes denominaciones como forma de identificarlos y ubicarlos en el rol de participación que les corresponde: Extraneus: se exterioriza cuando aquellas conductas en las cuales la autoría se ve caracterizada por el hecho de que alguien abusa o descuida el deber especial que surge de su rol social, y de ese modo, pone en peligro o lesiona determinados bienes jurídicos. Es decir, esa persona que reúne la condición exigida en el tipo penal para ser autor. Intraneus: es posible cuando concurre realmente complicidad, no goza de autonomía típica propia o autor del hecho punible. Extranei: o tercero al cargo público al no haber realizado acto material alguno para la realización del hecho.

El enfoque que se persigue en cuanto a las consecuencias jurídicas que conlleva el infringir unas normas que los establece, "son reparadoras", "preventivas", y "sancionadoras". El profesor Roxin: enseña que se trata de deberes que no se extienden a cualquier partícipe delictivo, pero que es indispensable para completar el tipo penal. Se trata siempre de deberes que lógicamente están ubicados antes de la norma penal y que, por lo general, surgen en otros ámbitos del derecho vigente. 
Roxin: es el penalista que introdujo en el Derecho Penal la categoría denominada delito de infracción de deber, desde su aparición, el delito de infracción de deber ha recorrido un camino escabroso en la discusión moderna en torno a la autoría delictiva. Por esta razón no es difícil observar diversas tomas de postura sobre el delito de infracción de deber, con voces autorizadas que lo admiten y otras que levantan reparos contra el mismo. Aunque también debe reconocerse que estas últimas se levantan la mayoría de veces más a causa de la novedad de los planteamientos que suscita el delito de infracción de deber en el debate de nunca acabar que se vive en el ámbito de la autoría delictiva, un terreno sobre el cual ya que opinó que probablemente se trate del "capítulo más oscuro y confuso de la ciencia del derecho penal."

Después de que la teoría subjetiva de la autoría se hiciera dominante en la jurisprudencia de los tribunales alemanes, sobre todo a partir de la segunda mitad del siglo XIX, gracias a la enorme influencia que sobre el derecho penal de la época ejerciera el magistrado del Tribunal del Imperio Maximilian V. Buri, la excesiva subjetivación de los criterios determinantes de la autoría condujo a esta teoría a una crisis que dio lugar a diversas objeciones contra ella. El poco peso del lado objetivo del hecho en la valoración era un dato que cada vez más se hacía visible en el momento de la determinación de la autoría y la participación. Autor sería aquél que considera el hecho como algo conforme a su voluntad, y cómplice quien mira el hecho según la voluntad del autor.

\section{Materiales y métodos}

Para el desarrollo de la presente investigación se utilizó material bibliográfico con contenidos relacionado al tema, el cual ha permitido concluir la presente investigación.

\section{Resultados}

Según la participación en el delito. Se considera necesario la implementación de una política criminal basada en hechos observados y comprobados, adecuados a la realidad social, que den forma a las herramientas que servirán para combatir esta clase de delitos, ya que la inexistencia de una regulación legal, teórica y filosófica en las negociaciones y preacuerdos para la aplicación del Derecho Penal, especialmente a los delitos de infracción de deber se encamina a la comisión de injustos penales.

\section{Discusión}

Se considera necesario establecer dos circunstancias básicas para la imposición de penas relativas a la participación en el delito. Primero: determinar claramente el concepto de autor director, inmediato o coautor y la participación de cada uno de ellos en la comisión de un ilícito. Segundo: las penas deben imponerse conforme al grado de participación o ejecución del delito, las cuales deben ser creadas conforme a políticas criminales. 
Lo anterior nace de la necesidad de brindar un aporte jurídico, que se cumpla y se respeten los principios y garantías constitucionales sobre los cuales se fundamenta el derecho penal guatemalteco, enfocado en los delitos de infracción de deber.

Primordial y necesario resulta mencionar que los delitos de infracción de deber, son delitos que pueden ser cometidos en el ámbito público por funcionarios públicos, que para ello es importante determinar la calidad de funcionario público, el puesto según el organigrama 0 jerarquía de quien comete esta clase de delitos, para poder determinar el grado de participación, debiendo para el efecto contar con la documentación que acredite tal calidad para poder materializar el delito de infracción de deber, el funcionario público para que tenga la calidad de autor debe tener un grado superior jerárquico para poder dar una orden a un subordinado y con ello se estaría consumando este delito, necesario resulta también mencionar que debe existir una relación laborar entre ambas personas, según el grado de participación al momento de ordenar y ejecutar las ordenes de un superior.

Existen personas que son empleadas de alguna dependencia del estado que por temor a represalias cumplen ordenes dentro del ámbito laborar sin imaginar que esta acción les podría llevar a consecuencias de tipo penal, pero es de tomar en cuenta que estas personas realizan en algunos casos estos actos por circunstancias de subordinación que existe, como anteriormente se mencionó, las represalias laborales pueden ser pérdida del empleo, cambio de condiciones de trabajo, reducción de salarios, como también represalias en el ámbito social, es decir que se tenga el temor a ser denigrados ante la sociedad lo que podría implicar que toda una sociedad juzgue a una persona por el simple hecho de un comentario que a mi juicio no debería ser posible.

Por las anteriores circunstancias, resulta importante recalcar que los delitos de infracción de deber, deben ser perseguidos penalmente, tomando en cuenta que en algunos casos intervienen varias personas, se debe determinar quién es autor directo, autor mediato y coautor y las formas de participación así como los elementos positivos y elementos negativos conforme al tipo, es evidente que en esta clase de delitos opera la teoría de dominio funcional del hecho, teoría en la cual los autores se asignan funciones para cometer un hecho, por lo que el Ministerio Público debe según la norma penal sustantiva, determinar claramente la participación en el delito, si fue la de autor director, inmediato o coautor y que en la acusación un acto posterior se le exige con mayor claridad el título de la imputación que debe dar a la persona que se está acusando, razón por la cual resultaría ilegitimo un acto del Ministerio Público o el Órgano Jurisdiccional no hacer esa distinción, lo anterior enfocado a no poner en peligro o lesión típica determinados bienes jurídicos.

\section{Referencias}

Cfr. Al Respecto Jakobs, Günther; La Imputación Penal De La Acción Y De La Omisión, Cuadernos De Conferencias Y Artículos $N^{\circ} 12$ De La Universidad Externado De Colombia, Bogotá, 1996, P. 18 Y Ss. https://dialnet.unirioja.es/descarga/articulo/246513.pdf 
Cfr. Roxin, Claus, Täterschaft Und Tatherrschaft, $1^{\circ}$ Ed., 1963, Pp. 352 Y Sshttps://dialnet.unirioja.es/descarga/articulo/5234891.pdf

Cfr. Schünemann, Bernd, El Dominio Sobre El Fundamento Del Resultado, Ob.Cit., 2006, P. 287. Aquí Se Sostiene Tal Como Enseña Roxin, Que Son Los Tipos Penales De La Parte Especial De Los Códigos Penales Que Describen El Hecho Y Que, De Ese Modo, Caracterizan Como Autor A Quien Pertenece A Esa Descripción. https://www.pj.gob.pe/ $\mathrm{wps} / \mathrm{wcm} /$ connect/e741c08041bf820599c2ff49cfca7f5d/la+teor\%c3\%8da+de+los+delitos+de+infracci\%c3\%93n+de+deber1-salinas. pdf?mod=ajperes\&cacheid=e741c08041bf820599c2ff49cfca7f5d

González Guerra, Carlos, Delitos De Infracción De Un Deber; Ad Hoc, Buenos Aires, 2006, P. 27 https://publicaciones.fder.edu.uy/index.php/idp/article/download/151/142/

Jakobs, Günther, Strafrecht. Allgemeiner Teil, Die Grundlagen Und Die Zurechnungslehre, $2^{\circ}$ Ed, Berlin/New York, 1991, P. 1/7; 7/56 Y Ss. http://www.pensamientopenal.com.ar/system/files/2018/05/doctrina46524.pdf

Pawlik, Michael, El Delito, ¿Lesión De Un Bien Jurídico?, Revista In Dret, Barcelona, 2016, P. 9 http://perso.unifr.ch/derechopenal/assets/files/anuario/an_2003_06.pdf

\section{Sobre el autor}

Bayron Eriberto Quiroa Vargas, es Licenciado en Ciencias Jurídicas y Sociales, Abogado y Notario, actualmente estudia la Maestría en Derecho Procesal Penal en el Centro Universitario ZACAPA.

\section{Financiamiento de la investigación}

Con recursos propios de los investigadores

\section{Declaración de intereses}

Declaran no tener ningún conflicto de intereses, que puedan haber influido en los resultados obtenidos o las interpretaciones propuestas.

\section{Declaración de consentimiento informado}

El estudio se realizó respetando el Código de ética y buenas prácticas editoriales de publicación. 


\section{Derechos de uso \\ Copyright@ 2021 por Bayron Eriberto Quiroa Vargas \\ Este texto está protegido por una licencia Creative Commons 4.0}

Este texto está protegido por la Licencia Creative Commons Atribución 4.0 Internacional.

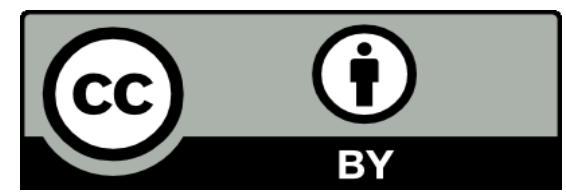

Este texto está protegido por una licencia

Creative Commons 4.0.

Es libre para compartir, copiar y redistribuir el material en cualquier medio o formato y adaptar el documento, remezclar, transformar y crear a partir del material para cualquier propósito, incluso comercialmente, siempre que cumpla la condición de atribución: debe reconocer el crédito de una obra de manera adecuada, proporcionar un enlace a la licencia, e indicar si se han realizado cambios. Puede hacerlo en cualquier forma razonable, pero no de forma tal que sugiera que tiene el apoyo del licenciante o lo recibe por el uso que hace. 